УДК 338.24

$10.17213 / 2075-2067-2021-3-162-181$

\title{
ПОСТРОЕНИЕ ТРЕНДОВ РАЗВИТИЯ ПРЕДПРИЯТИЙ ТОПЛИВНО-ЭНЕРГЕТИЧЕСКОГО КОМПЛЕКСА РФ В УСЛОВИЯХ ЦИФРОВОЙ ТРАНСФОРМАЦИИ БИЗНЕСА
}

\author{
(С) 2021 г. И. М. Зайченко , А. М. Фадеев, ${ }^{* * *}$, А. И. Костюченко \\ "Санкт-Петербургский политехнический университет Петра Великого, \\ 2. Санкт-Петербург, Россия \\ ** Институт экономических проблем им. Г. П. Лузина, г. Апатиты, Россия
}

Целью исследования является построение трендов развития предприятий ТЭК РФ в условиях ичифровой трансформации экономики.

Методологическую базу исследования представляет анализ сущности иุифровой трансформации и концепџии Industry 4.0, сравнительный анализ перспективных ијифровых технологий для ТЭК РФ. Ключевым методом исследования стал графический метод. Построение причинно-следственной диаграммы Исикавы на основе анализируемых факторов и определило тренды развития предприятий ТЭК РФ в условиях иүифровой трансформачии.

Результаты исследования. Описана сущность ичифровой трансформаџии предприятий ТЭК РФ в рамках реализаџии конщепџии Industry 4.0, проанализированы предпосылки проведения ичифровой трансформаџии предприятий ТЭК РФ, проведен анализ перспективных технологий и возможностей их применения на месторождениях. В условиях развития и внедрения иифровых технологий на предприятиях ТЭК встает вопрос о том, каким путем будут развиваться эти предприятия. Для определения пути развития бьл рассмотрен успешный опыт внедрения цифровых технологий в российских нефтегазовых компаниях. Выявлены и охарактеризованы предпосылки и причины ичифровой трансформации деятельности предприятий топливно-энергетического комплекса Российской Федераџии. На основе проанализированной информаџии были построень тренды развития российского топливно-энергетического комплекса в условиях ичифровой трансформации. Тренды были выстроены с помощью причинно-следственной диаграммы Исикавы. Построенные диаграммы указали на два тренда развития ТЭК РФ в условиях ичифровой трансформации: развитие нетрадиционных месторождений и месторождений Арктического шельфа.

Перспективу исследования составляет более углубленный анализ политических, экономических, сочиальных и экологических факторов, использование различного набора инструментов и методов для построения трендов. Также перспективой для исследования может быть более глубокий анализ политики Российской Федераџии по отнотению к нефтегазовой отрасли.

Ключевые слова: Industry 4.0; предприятия ТЭК РФ; ичифровая трансформащия; арктические месторождения; нетрадиционные месторождения; тренды развития предприятий ТЭК РФ; информационно-коммуникационные технологии. 


\title{
BUILDING DEVELOPMENT TRENDS OF ENTERPRISES OF THE FUEL AND ENERGY COMPLEX OF THE RUSSIAN FEDERATION IN THE CONDITIONS OF DIGITAL TRANSFORMATION OF BUSINESS
}

\author{
(C) 2021 I. M. Zaychenko*, A. M. Fadeev ${ }^{*, * *}$, A. I. Kostyuchenko* \\ "Peter the Great St. Petersburg Polytechnic University, Saint Petersburg, Russia

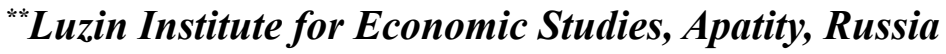

The aim of the study is to build trends in the development of enterprises in the fuel and energy complex of the Russian Federation in the context of digital transformation of the economy.

The methodological basis of the study is the analysis of the essence of digital transformation and the concept of Industry 4.0. Comparative analysis of promising digital technologies for the fuel and energy complex of the Russian Federation. The graphical method has become the key research method. The construction of a causal diagram of Ishikawa based on the analyzed factors determined the development trends of enterprises in the fuel and energy complex of the Russian Federation in the context of digital transformation.

The results of the study. The essence of the digital transformation of enterprises in the fuel and energy complex of the Russian Federation is described in the framework of the implementation of the Industry 4.0 concept, the prerequisites for the digital transformation of enterprises in the fuel and energy complex of the Russian Federation are analyzed, and promising technologies and the possibilities of their application in the fields are analyzed. In the context of the development and implementation of digital technologies at the enterprises of the fuel and energy complex, the question arises of how these enterprises will develop. To determine the development path, the successful experience of introducing digital technologies in Russian oil and gas companies was considered. The prerequisites and reasons for the digital transformation of the activities of enterprises of the fuel and energy complex of the Russian Federation are identified and characterized. Based on the analyzed information, trends in the development of the Russian fuel and energy complex in the context of digital transformation were built. The trends were built using the Ishikawa causal diagram. The constructed diagrams indicated 2 trends in the development of the Russian fuel and energy complex in the context of digital transformation: the development of unconventional fields and fields on the Arctic shelf.

The prospect of the study is a more in-depth analysis of political, economic, social and environmental factors. Using a different set of tools and methods for building trends. A deeper analysis of the policy of the Russian Federation in relation to the oil and gas industry can also be a prospect for the study.

Key words: Industry 4.0; enterprises of the Russian fuel and energy complex; digital transformation; arctic fields; unconventional fields; development trends of enterprises of the Russian fuel and energy complex; information and communication technologies.

Введение. В настоящее время истощение традиционных запасов нефти и газа вызывает необходимость разработки трудноизвлекаемых запасов, более того, разработки с применением новых технологий разведки и добычи углеводородов в труднодоступных районах
Восточной Сибири и на Арктическом шельфе. Решение этих проблем требует интенсификации внедрения информационных технологий в нефтегазовом комплексе.

В настоящее время в нефтегазовом комплексе РФ происходит интенсивная цифровая 
трансформация. Предприятия ТЭК осваивают новые информационно-коммуникационные технологии, чтобы удержать свои конкурентные преимущества в ближайшие годы.

Очевидно, что внедрение информационно-коммуникационных технологий - инструмент повышения экономической эффективности разработки нефтяных и газовых месторождений. Использование данных технологий позволяет оптимизировать производственные затраты, а также повысить эффективность документооборота, логистики и финансовых операций.

Несмотря на то, что российские технологии и оборудование, применяемые в нефтегазовой отрасли, претерпели в последнее время существенную модернизацию, все равно российские геологоразведочные работы, добыча и транспортировка нефти и газа явно отстают от зарубежного уровня.

Это связано с тем, что до последнего времени развитие этого сектора происходило по пути экстенсивного способа. Однако под влиянием современных вызовов экономики, а именно: исчерпания традиционных месторождений; изменения структуры энергетического баланса, структуры мирового рынка; достаточно высокой волатильности цен на нефть и газ; появления нового оборудования и технологий по добыче ранее недоступных энергетических ресурсов — вызывает необходимость создания новых и удержание существующих конкурентных преимуществ, что возможно лишь при переходе на интенсивный путь развития предприятий ТЭК в нашей стране.

Применение информационно-коммуникационных технологий может способствовать скорейшему переходу на интенсивный путь развития предприятий ТЭК.

Изменения становятся настолько кардинальными, что новый период развития ТЭК ознаменован новой парадигмой развития. Одной из основных движущих сил новой парадигмы развития является активная реализация концепции «Industry 4.0 ».

Современные цифровые технологии смещают тренды развития ТЭК РФ и мира в сторону ранее недоступных месторождений Арктики.

Таким образом, целью данной работы является построение трендов развития пред- приятий ТЭК РФ в условиях цифровой трансформации экономики.

Задачи: охарактеризовать сущность цифровой трансформации ТЭК; сделать обзор перспективных цифровых технологий ТЭК; изучить лучшие практики цифровой трансформации компаний России; описать глобальные, локальные причины и предпосылки цифровой трансформации предприятий топливноэнергетического комплекса; построить тренд на развитие арктических территорий в условиях цифровой трансформации; построить тренд развития нетрадиционных месторождений в условиях цифровой трансформации.

Объектом работы являются предприятия ТЭК РФ.

Предметом - тренды развития предприятий ТЭК РФ.

Актуальность исследования состоит в том, что современные реалии топливноэнергетического комплекса достаточно негативные. Переизбыток нефти на мировом рынке, низкие цены на нефть, высокая волатильность цен, санкционные и торговые войны, а также исчерпание традиционных месторождений, изменение энергетического баланса и цифровая трансформация как ТЭК, так и других отраслей заставляют нефтегазовые предприятия менять свой путь развития. По какому пути будет идти развитие предприятий ТЭК - один из актуальных вопросов на сегодняшний день, так как топливноэнергетический комплекс является одним из драйверов российской экономики.

В настоящее время в научной литературе появилось большое количество работ, посвященных вопросам осуществления деятельности в рамках реализации концепции Industry 4.0 в целом, особенностям проведения цифровой трансформации предприятий ТЭК в частности. Все многообразие научных исследований можно разделить на несколько больших групп.

Первая группа работ [1-4] носит общий характер и представляет собой описание общих условий проведения цифровой трансформации, трактовки понятия Industry 4.0, характеристики ее основных направлений, выявления отличий от Industry 3.0.

Следующая группа работ [5-8] посвящена характеристике самых часто используемых, а потому, возможно, наиболее перспек- 
тивных с точки зрения применения на предприятиях ТЭК РФ информационно-коммуникационных технологий. Есть отдельные исследования [9], которые построены на эмпирическом анализе применения данных технологий в нефтегазовой сфере, выявлены преимущества и недостатки их применения.

Интересным является анализ рисков и барьеров цифровой трансформации предприятий нефтегазового сектора $[10,11]$.

Опыт внедрения цифровых технологий в российских компаниях на примере ПАО «Газпром нефть» представлен в $[12,13]$, в которых описаны возможности применения информационно-коммуникационных технологий в различных сферах, обоснованы экономическая эффективность и применение.

Региональные особенности внедрения цифровых технологий представлены в [1418], авторы исследовали развитие нефтегазовых предприятий в Арктической зоне, сложности и перспективы.

Предпосылки, глобальные и локальные причины цифровой трансформации предприятий ТЭК выявлены, охарактеризованы и проанализированы в [19-22]. Данная группа работ представляет наибольший интерес и может составить базу для дальнейшего построения трендов развития предприятий ТЭК РФ.

Последняя группа научных исследований [23-26] представляет собой оценку влияния перспектив применения цифровых технологий в нефтегазовой сфере, в частности влияния цифровых технологий на геологоразведочные работы и преимущества цифровой трансформации деятельности при проведении данного типа работ.

Таким образом, проведенный обзор литературы показал, что существует достаточно большое количество научных исследований, посвященных цифровой трансформации российского топливно-энергетического комплекса, возможностям применения информационно-коммуникационных технологий в нефтегазовом комплексе, но ни в одном из рассмотренных исследований нет построения или описания возможных трендов развития топливно-энергетического комплекса РФ в условиях цифровой трансформации экономики, что еще раз подтверждает актуальность данного исследования.
Теоретические основы цифровой трансформации ТЭК. Структурный кризис российской экономики полностью проявил себя во втором десятилетии XXI века и предопределил необходимые изменения в отечественных отраслях. Эти изменения, безусловно, должны основываться на широко распространенных в мире инновациях.

Качественный скачок развития многих отраслей неразрывно связан с использованием современного оборудования и передовых информационно-коммуникационных технологий, а также их применения.

Концепция Industry 4.0 включает в себя не только цифровизацию, но и интеграцию каждого из процессов жизненного цикла в единое целое [1]. Информация обо всех текущих процессах, ступенях производства, деталях, сборочных единицах и продукции должна быть доступна всем авторизованным пользователям в режиме онлайн в единой информационной системе. Бизнес-интеграция осуществляется как по вертикали, так и по горизонтали, влияя и привлекая все большее количество деловых партнеров в цепочке создания стоимости. Потребители и клиенты также вовлекаются в единую интегрированную экосистему создания стоимости.

Учитывая факт повсеместного использования прорывных (информационно-коммуникационных) технологий во всех отраслях социально-экономической жизни общества, можно утверждать, что существует и широчайший потенциал для применения их и на предприятиях ТЭК РФ, что позволит обеспечить достаточно высокий уровень инновационного развития данных предприятий. За исключением сектора разведки полезных ископаемых, современные добывающие отрасли имеют тенденцию доминировать на мировом рынке над другими отраслями. Последний сырьевой бум привел к эскалации слияний и приобретения среди уже высококонцентрированных компаний. Потребность добывающих отраслей в использовании современных информационно-коммуникационных технологий может привести к более эффективному взаимодействию между добывающими отраслями и технологиями разработчиков. Добывающие отрасли должны изучить возможности сотрудничества между ключевыми игроками. Цифровизация 
дает возможность новаторским российским и иностранным технологиям улучшить жизнеспособность добывающих отраслей [2].

Таким образом, применение концепции Industry 4.0 получило определенное развитие и в топливно-энергетическом комплексе, трансформировавшись в концепции «Energy 4.0» и «Oil and Gas 4.0». Цифровая трансформация в нефтегазовой отрасли развивается в двух направлениях: так называемые «Цифровой upstream» и «Цифровой downstream». Мировая история нефтегазовой отрасли показывает, что сектор «upstream» в плане внедрения новых технологий развивается быстpee, чем «downstream», ввиду более высокой рентабельности. Однако полный переход к реализации концепции Industry 4.0 повлечет за собой ряд изменений. Ключевой технологией, которая составит основу всех технологических изменений и улучшений, будет «Интернет вещей».

Данная технология является главной технологией Индустрии 4.0. Она позволяет в режиме реального времени контролировать и получать все данные обо всех процессах за счет совместной работы программного обеспечения и аппаратных средств. В таблице 1 на основе [3, 4] представлено сравнение парадигмы Industry 3.0 и Industry 4.0 в аспекте развития предприятий энергетического сектора.

Всеобъемлющая долгосрочная поддержка развития, применения и внедрения цифровых технологий во всех сферах ТЭК РФ будет служить драйвером для выхода энергетической и топливной отрасли на новый уровень развития, позволит сохранять сильные конкурентноспособные позиции всего топливно-энергетического комплекса на мировой арене и доминировать на мировом рынке научно-технических знаний и технологий.

Далее в таблице 2 представлен анализ возможностей применения информационнокоммуникационных технологий в нефтегазовом секторе [5-9].

Анализ возможностей применения информационно-коммуникационных технологий в нефтегазовом секторе был бы неполным без рассмотрения так называемых рисков их применения на данных предприятиях [10, 11], а именно:

1) сильная потребность и зависимость от западных технологий и нестабильная по- литическая обстановка способствуют увеличению влияния санкций на важнейшие направления деятельности топливно-энергетических компаний России. В России для уменьшения зависимости от технологий Запада и уменьшения санкционного влияния проводится политика импортозамещения и поддержка отечественных разработок;

2) тяжелые условия эксплуатации цифровых технологий ведут к повышенным требованиям защищенности от таких факторов, как воды, холода, влажности, что ведет к удорожанию для конечного потребителя и несет дополнительные экономические и экологические риски;

3) также при внедрении цифровых технологий в логистику освоения нефтегазовых месторождений возникает угроза кибер-атак, захвата контроля над датчиками и системами, что несет очень серьезные последствия для компаний;

4) высокая волатильность мировых цен на нефть и газ ставят под угрозу проекты по цифровизации как добычи, так и логистики нефтегазового комплекса. Цифровые технологии дорогие, что при высокой волатильности и низких ценах делает их недоступными для компаний, при этом возрастают экономические риски. Такие проекты по цифровизации имеют большой срок окупаемости, что при нестабильной экономической обстановке в мире может превратиться в убыточный проект;

5) высокотехнологичных компаний, которые занимаются разработкой и производством цифровых технологий для нефтегазового комплекса, мало, что создает угрозу попадания в зависимость и монополизации рынка цифровых решений для нефтегазового комплекса.

При этом при анализе возможностей применения информационно-коммуникационных технологий на предприятиях нефтегазового комплекса нельзя не учитывать положительный опыт. Так, ПАО «Газпром нефть» имеет опыт успешного использования цифрового симулятора Cyber Fracturing 2.0 в своих активах. Это программное обеспечение моделирует создание гидроразрыва (ГРП), а также находит лучшие алгоритмы для геологических операций. В сочетании с другими цифровыми инструментами «Газпром нефти» данная технология позволя- 
Сравнительный анализ развития энергетического сектора в формате Industry Industry 4.0

\begin{tabular}{|c|c|c|}
\hline $\begin{array}{l}\text { рии } \\
\text { ния }\end{array}$ & $\begin{array}{c}\text { Старая парадигма развития } \\
\text { энергетического сектора } \\
\text { в формате Industry } 3.0\end{array}$ & $\begin{array}{c}\text { Новая парадигма развития } \\
\text { энергетического сектора } \\
\text { в формате Industry } 4.0\end{array}$ \\
\hline Резервы & $\begin{array}{l}\text { Крупные и сверхкрупные } \\
\text { месторождения с традицион- } \\
\text { ными ресурсами }\end{array}$ & $\begin{array}{l}\text { Малые и средние месторождения, также } \\
\text { месторождения с ТРИЗами }\end{array}$ \\
\hline $\mathrm{b}$ & $\begin{array}{l}\text { До } 30-\text { Х гг. XX века - уголь, } \\
\text { до } 80-\text { - гг. XX века- нефть }\end{array}$ & Гибридные ресурсы — «mix energy» \\
\hline бала & Один ресурс (нефть или уголь) & , все ис \\
\hline суб & Разведка и добыча & Все уровни (upstream, midstream, downstream) \\
\hline & $\begin{array}{l}\text { Экстенсивные технологии до- } \\
\text { бычи, стандартизация }\end{array}$ & $\begin{array}{l}\text { Цифровые технологии } \ln \\
\text { «точно в срок» и «бережли }\end{array}$ \\
\hline $\begin{array}{l}\text { Подход к орга- } \\
\text { низации про- } \\
\text { изводства } \\
\text { секторе }\end{array}$ & $\begin{array}{l}\text { Преимущественно экстенсив- } \\
\text { ное развитие с элементами } \\
\text { интенсификации некоторых } \\
\text { базовых производств, четкое } \\
\text { разграничение между субсек- } \\
\text { торами и отраслями } \\
\end{array}$ & $\begin{array}{l}\text { В основном интенсивное развитие в основе } \\
\text { учета локальных особенностей. Гибкость и } \\
\text { мобильность добычи и поставок ресурсов } \\
\text { на основе блоков и модулей. Нет четких } \\
\text { границ между субсекторами и отраслями }\end{array}$ \\
\hline $\begin{array}{l}\text { Цеп } \\
\text { пост }\end{array}$ & $\begin{array}{l}\text { кальные, высо- } \\
\text {, глобальные }\end{array}$ & $\begin{array}{l}\text { Открытые, низкие, разветвленные, нисхо- } \\
\text { дящие. Ведущая роль принадлежит сервис- } \\
\text { ным, проектным и научно-исследовательским } \\
\text { структурам. Национальные и локализованные }\end{array}$ \\
\hline Рынок & $\begin{array}{l}\text { Інок продавца. Глобальный } \\
\text { Інок }\end{array}$ & $\begin{array}{l}\text { Рынок покупателя. Растущая роль нацио- } \\
\text { нальных и локальных рынков }\end{array}$ \\
\hline $\begin{array}{l}\text { Осно } \\
\text { комП }\end{array}$ & Глобальные ВИНК & $\begin{array}{l}\text { Большое разнообразие компаний, в том } \\
\text { числе и национальные и малые компании }\end{array}$ \\
\hline $\begin{array}{l}\text { зая } \\
\text { взаимо- } \\
\text { ия }\end{array}$ & $\begin{array}{l}\text { Глобальная конкуренция } \\
\text { доступные запасы }\end{array}$ & $\begin{array}{l}\text { Конкуренция и сотрудничество на основе } \\
\text { совместного доступа к уникальным немате- } \\
\text { риальным активам и компетенциям }\end{array}$ \\
\hline $\begin{array}{l}\text { Основные } \\
\text { и с т о ч н и к и } \\
\text { конкурентос- } \\
\text { пособности }\end{array}$ & $\begin{array}{l}\text { Высокое качество и доступ- } \\
\text { ность запасов. Цена ресурса. } \\
\text { Снижение затрат на добычу } \\
\text { ресурса }\end{array}$ & $\begin{array}{l}\text { Гибкость добычи и доставки энергоресур- } \\
\text { сов. Качество ресурсов и неценовые фак- } \\
\text { торы. Снижение затрат во всех сегментах } \\
\text { энергетического сектора }\end{array}$ \\
\hline Базо & $\begin{array}{l}\text { Природная рента от использо- } \\
\text { вания минеральных энергоре- } \\
\text { сурсов }\end{array}$ & $\begin{array}{l}\text { Снижение роли природной ренты и рост } \\
\text { роли предпринимательского дохода }\end{array}$ \\
\hline $\begin{array}{l}\text { Подходы к го- } \\
\text { сударственно- } \\
\text { му регулирова- } \\
\text { нию энергети- } \\
\text { ческого сектора }\end{array}$ & $\begin{array}{l}\text { Минимальное вмешательство } \\
\text { в деятельность рынка. Кос- } \\
\text { венные административные } \\
\text { меры }\end{array}$ & $\begin{array}{l}\text { Растущее вмешательство государства, под- } \\
\text { держка новых технологий, компетенций, } \\
\text { кооперация, ГЧП. Поддержка малого и } \\
\text { среднего бизнеса }\end{array}$ \\
\hline
\end{tabular}




\section{Возможности применения информационно-коммуникационных технологий в нефтегазовом секторе}

\begin{tabular}{|c|c|}
\hline Технология & Возможность применения в нефтегазовом комплексе \\
\hline $\begin{array}{l}\text { ІоТ (Интернет } \\
\text { вещей) }\end{array}$ & $\begin{array}{l}\text { Существует множество вариантов использования Интернета вещей в } \\
\text { нефтегазовой отрасли на разных этапах этой цепочки поставок. Груп- } \\
\text { па компаний Endress + Hauser, например, предлагает платформу ІоТ } \\
\text { Netilion и комплекс инструментов для профилактического обслужива- } \\
\text { ния, максимизации производительности и повышения безопасности на } \\
\text { заводах и других звеньях цепочки создания стоимости в нефтегазовой } \\
\text { отрасли. Еще одно приложение ІоТ в нефтегазовой отрасли, созданное } \\
\text { Intelligent Sensing Anywhere в сотрудничестве с Telit, сфокусировано на } \\
\text { телеметрии резервуаров и охватывает рынок сбыта продукции. Осна- } \\
\text { щая топливные и газовые цистерны беспроводными датчиками, ком- } \\
\text { пании обеспечивают удаленный мониторинг и предоставляют своим } \\
\text { клиентам подробную картину эксплуатации цистерн. Многие компа- } \\
\text { нии корпоративного уровня, лидеры рынка }\end{array}$ \\
\hline $\begin{array}{l}\text { Интеллектуальные } \\
\text { датчики }\end{array}$ & $\begin{array}{l}\text { Одним из важнейших условий эффективной добычи нефти и газа явля- } \\
\text { ется профилактическое обслуживание и регулярный ремонт оборудова- } \\
\text { ния. Однако, несмотря на строгое соблюдение графиков технического } \\
\text { обслуживания, надежность оборудования довольно низкая. В результате } \\
\text { компаниям необходимо поддерживать на платформах большое количе-- } \\
\text { тво обслуживающего персонала. Эта проблема решается с помощью } \\
\text { системы прогнозной аналитики. Системная установка датчиков, соби- } \\
\text { рающих различные данные о работе устройств, а также программное } \\
\text { обеспечение для анализа работоспособности оборудования и хода ре- } \\
\text { монтных работ позволяет решить многие проблемы до того, как они по- } \\
\text { явились. В то же время есть предпосылки для оптимизации количества } \\
\text { ремонтных бригад на 15-20\% и сокращения времени простоя оборудова- } \\
\text { ния для планово-предупредительных и капитальных ремонтов }\end{array}$ \\
\hline $\begin{array}{l}\text { Дополненная } \\
\text { реальность }\end{array}$ & $\begin{array}{l}\text { Приложения AR могут помочь повысить безопасность на месторож- } \\
\text { дениях за счет эффективной передачи необходимой информации в } \\
\text { режиме реального времени. На рабочих местах в нефтегазовой отрас- } \\
\text { ли должны соблюдаться строгие правила техники безопасности из-за } \\
\text { опасной рабочей среды и наличия легковоспламеняющихся веществ. } \\
\text { Своевременная информация и инструкции могут быть наложены на } \\
\text { полевого работника, чтобы предпринять соответствующие действия } \\
\text { для обеспечения безопасного выполнения любой задачи. Нефтегазо- } \\
\text { вые компании сотрудничают с такими технологическими компаниям, } \\
\text { как Мicrosoft и Google для разработки отраслевых решений AR. Техно- } \\
\text { логические стартапы также присоединяются к усилиям по разработке } \\
\text { индивидуальных решений дополненной реальности для конкретных } \\
\text { нужд нефтегазовых компаний }\end{array}$ \\
\hline $\begin{array}{l}\text { Моделирование и } \\
\text { прогнозирование } \\
\text { на основе продви- } \\
\text { нутой аналитики } \\
\text { и технологий Big } \\
\text { Data }\end{array}$ & $\begin{array}{l}\text { Big Data аналитика может быть использована для повышения безо- } \\
\text { пасности труда в нефтегазовой отрасли. Сначала необходимо выпол- } \\
\text { нить сбор и обработку данных. Затем надо структурировать данные по } \\
\text { формату, чтобы представить легко понятный результат для принятия } \\
\text { управленческого решения и минимизирования шанса на травму или } \\
\text { поломку оборудования }\end{array}$ \\
\hline
\end{tabular}




\begin{tabular}{|l|l|}
\hline B последние годы нефтегазовая промышленность демонстрирует \\
медленное, но устойчивое внедрение 3D-печати. Первоначально эта \\
технология была в основном ограничена продуктами на основе поли- \\
меров. Однако недавние достижения в области 3D-печати на основе \\
металла делают эту технологию более актуальной для нефтегазовой \\
отрасли. Ключевое преимущество технологии 3D-печати заключает- \\
ся в сокращении времени, необходимго для изготовления сложных \\
прототипов. 3D-принтеры также могут сократить время, необхдимое \\
для производства функциональных продуктов? для использования в \\
производственной деятельности. Из-за более строгих экологических \\
норм, неустойчивых цен на нефть и постоянно растущей конкурен- \\
ции компании тяготеют к сложным конструкция оборудования для \\
достижения операционной эффективности. Возможность производить \\
сложные компоненты, которые в противном случае невозможно было \\
бы изготовить с использованием обычных процессов, превращает 3D- \\
печать в обязательную технологию. Длительные процессы закупки \\
запасных частей часто вынуждают нефтегазовые компании поддержи- \\
вать чрезвычайно высокий уровень запасов, что приводит к затратам \\
на складское хранение
\end{tabular}

ет повысить эффективность добычи нефти из низкопроницаемых резервуаров на $5 \%$. В долгосрочной перспективе экономический эффект от внедрения цифрового инструмента оценивается в 4,8 млрд. рублей дополнительной прибыли.

Пилотный проект по использованию блокчейна в логистике был реализован компаниями «Газпромнефть-Снабжение» и «Газпром нефть шельф» при доставке арматуры на МЛСП «Приразломная». Для того чтобы данные о движении груза записывались в блокчейн автоматически, на груз на заводе в Великом Новгороде были нанесены радиочастотные метки (RFID) и установлены датчики GPS.

Чтение RFID-метки также позволило быстро получить доступ к информации о генеральном грузе и отсканированных копиях сопроводительных документов в формате PDF. Технология позволила автоматизировать все складские операции и контролировать их выполнение в установленные сроки $[12,13]$

Очевидно, что реализация крупнейших нефтегазовых проектов в арктических условиях требует нового подхода и технологических решений для эффективного освоения углеводородов на шельфе. Компании, имеющие необходимые лицензии для разработки шельфовых месторождений, стремятся следовать цифровым трендам отрасли и активно внедряют инновационные технологии в рамках масштабных инвестиционных проектов, таких как «Новый порт» и «Приразломная» («Газпром»), «Северная оконечность месторождения «Чайво» и «Сахалин-1» («Роснефть»).

Это также подтверждается тем, что ведущие компании уже реализуют долгосрочные планы по развитию цифровых технологий. Так, согласно стратегии «Роснефть-2022» компания отдает приоритет развитию потенциала цифровизации и прорывным технологическим решениям. В рамках нефтегазовых проектов по освоению шельфовой и материковой территорий Российской Федерации активно развиваются концепция «Цифровое месторождение», индустриальный интернет, технологии Больших Данных и удаленное управление бурением и добычей. Между тем, цифровая стратегия ПАО «Газпром нефти» включает основные направления, объединяющие всю цепочку создания стоимости и управления бизнес-процессами. Приоритет отдается таким аспектам, как создание единой 
цифровой платформы управления бизнесом и систем управления данными. Всеми производственными активами можно будет управлять из единого центра, что позволит значительно повысить эффективность бизнеспроцессов, а также наладить коммуникации между блоками компании, увеличив скорость принятий технологических и организационных решений.

Ключевые направления стратегии технологических преобразований компании ПАО «Газпром Нефть»:

- когнитивная геологоразведка (применение искусственного интеллекта в поиске промышленных запасов нефти и оценке вероятности успеха того или иного проекта);

- когнитивный инжиниринг (формирование схемы разработки месторождения с помощью машинного обучения);

- корпоративный центр управления бурением (дистанционный контроль производственных объектов);

- центр управления добычи (объединение всех производственных процессов добычи в единую интегрированную среду);

- цифровые двойники (создание прототипов реальных объектов в виртуальной среде поиска оптимальных решений).

Ключевые аспекты стратегии «Роснефть-2022»:

- запуск корпоративного центра обработки данных с платформой индустриального интернета и интегрированного цифрового двойника месторождений;

- испытания технологии мониторинга производственных объектов с помощью дронов и машинного зрения, применения искусственного интеллекта при разработке месторождений;

- тестовые испытания системы мониторинга ледовой установки для бурения на шельфе;

- введение систем предиктивной аналитики и индикаторов состояния динамического оборудования.

Технологии, которые не предполагают непосредственного присутствия людей на объекте, проще говоря? «безлюдные», уже стали активно внедряться и использоваться на отечественных предприятиях для добычи нефти. Так, например, в ООО «ГазпромнефтьХантос» (дочернее предприятие ПАО «Газ- промнефть») производственные процессы на Южно-Приобском месторождении обслуживаются из центрального офиса компании благодаря цифровому двойнику месторождения. По предварительным оценкам, с запуском системы цифрового двойника эксплуатационные расходы на разработку месторождения могут сократиться на 15\% [14-18].

Данные примеры использованы для того, чтобы показать, что цифровые технологии уже используются и активно внедряются в ТЭК РФ, также у российских компаний есть опыт использования таких технологий, и они используются на нетрадиционных месторождениях и на Арктическом шельфе. Это дает основание полагать, что предприятия ТЭК РФ все-таки ориентированы на интенсивный путь развития.

Предпосылки перехода предприятий ТЭК к цифровой трансформации. Построение трендов развития предприятий ТЭК РФ невозможно без анализа предпосылок проведения цифровой трансформации данных предприятий, так как качественный анализ причин перехода к цифровой трансформации дает возможность более точного прогнозирования социально-экономических и экологических последствий их внедрения на предприятиях ТЭК РФ. В таблице 3 представлены предпосылки цифровой трансформации предприятий топливно-энергетического комплекса и причины их возникновения [19-22].

Как видно из таблицы 3, причин как глобальных, так и локальных достаточно для того, чтобы цифровая трансформация охватила все сферы деятельности предприятий топливно-энергетического комплекса. Проведенный анализ также показал, что в целом ТЭК РФ готов к этой трансформации.

Построение трендов развития ТЭК РФ. Далее в соответствии с целью исследования были построены тренды развития ТЭК РФ в условиях цифровой трансформации экономики.

Проведенный анализ также позволил выявить два приоритетных тренда в современном развитии предприятий топливно-энергетического комплекса РФ:

1) тренд на освоение арктических месторождений в условиях цифровой трансформации; 


\section{Предпосылки к цифровой трансформации ТЭК РФ}

\begin{tabular}{|c|c|}
\hline Предпосылки & Причины \\
\hline \multirow{13}{*}{ 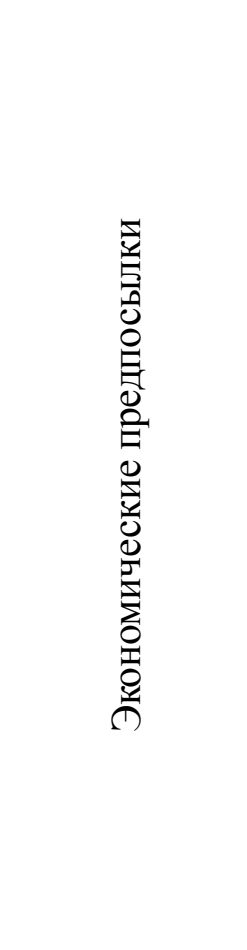 } & Глобальные причины: \\
\hline & 1) рост городского населения \\
\hline & $\begin{array}{l}\text { 2) недостаток инвестиционных вложений в модернизацию инфраструктуры } \\
\text { топливно-энергетического комплекса }\end{array}$ \\
\hline & $\begin{array}{l}\text { 3) новые бизнес-модели, основанные на парадигме «цифрового бизнеса» че- } \\
\text { рез одноранговые и прозрачные транзакции }\end{array}$ \\
\hline & 4) сегментация рынка по платежеспособному спросу \\
\hline & 5) экономическая нестабильность \\
\hline & Локальные причинь:: \\
\hline & $\begin{array}{l}\text { 6) истощение традиционных ресурсов углеводородов и смещение произ- } \\
\text { водства в сторону нефти и сланцевого газа и арктической платформы }\end{array}$ \\
\hline & $\begin{array}{l}\text { 7) отсутствие окупаемости российского рынка сбыта высокотехнологичных } \\
\text { инноваций и энергоэффективного оборудования }\end{array}$ \\
\hline & 8) проблемы роста коммерческих потерь и неэффективности энергокомпаний \\
\hline & 9) ежегодный рост тарифов на энергоресурсы и затрат населения на их оплату \\
\hline & 10) низкая энергоэффективность экономики России \\
\hline & 11) зависимость отрасли от зарубежных технологий и оборудования \\
\hline \multirow{11}{*}{ 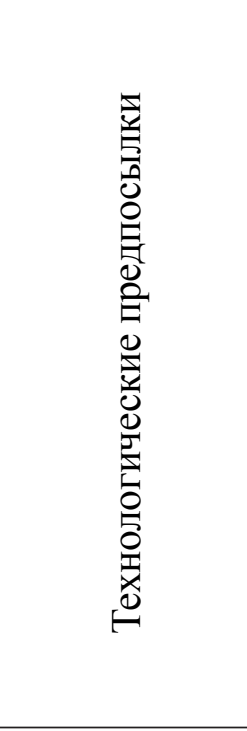 } & Глобальные причины: \\
\hline & $\begin{array}{l}\text { 1) рост спроса на надежное и качественное оборудование и менеджмент в } \\
\text { топливно-энергетическом комплексе }\end{array}$ \\
\hline & 2) рост потребления углеводородов \\
\hline & 3) развитие городов и городских агломераций \\
\hline & 4) общая тенденция к децентрализации \\
\hline & 5) разработка инновационных технологий, устройств и материалов \\
\hline & 6) масштабное развитие распределенной энергетики \\
\hline & Локальные причиныл: \\
\hline & $\begin{array}{l}\text { 7) моральное устаревание инфраструктуры (износ ТЭК достигает 66\%) и ло- } \\
\text { гики развития энергосистемы }\end{array}$ \\
\hline & 8) техническое состояние производственных фондов \\
\hline & 9) отсутствие наблюдаемости сетевых объектов и режимов работы \\
\hline \multirow{4}{*}{ 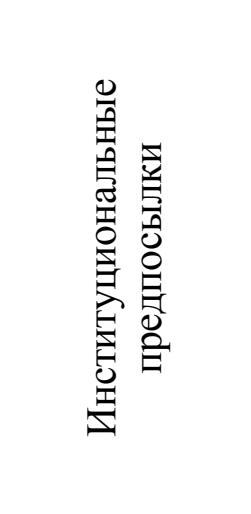 } & Глобальные причины:: \\
\hline & $\begin{array}{l}\text { 1) объединенит усилий всех заинтересованных сторон, а именно отраслевого } \\
\text { бизнес-сообщества, органов власти, научно-исследовательских организаций } \\
\text { и образовательных учреждений }\end{array}$ \\
\hline & $\begin{array}{l}\text { 2) дефицит системных мер по стимулированию коммерциализации иннова- } \\
\text { ций в компаниях ТЭК }\end{array}$ \\
\hline & $\begin{array}{l}\text { 3) необходимость внесения поправок в законы в связи с появлением новых } \\
\text { субъектов (просьюмеров, активных потребителей, агрегаторов), регулирова- } \\
\text { ния отношений между ними, стандартизации интерфейсов взаимодействия с } \\
\text { Единой энергетической системой }\end{array}$ \\
\hline
\end{tabular}


Окончание таблицы 3

\begin{tabular}{|c|c|}
\hline \multirow{3}{*}{ 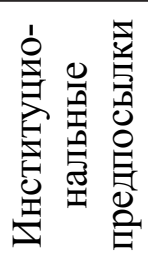 } & Локальнье причинь:: \\
\hline & $\begin{array}{l}\text { 4) необходимость мгновенных откликов на неисполнение обязательств учас- } \\
\text { тниками рынка }\end{array}$ \\
\hline & $\begin{array}{l}\text { 5) необходимость стимулирования повышения энергоэффективности и энер- } \\
\text { госбережения }\end{array}$ \\
\hline \multirow{8}{*}{$\begin{array}{l}5 \\
\text { 总 } \\
0 \\
0 \\
0 \\
0 \\
0 \\
0 \\
0 \\
0 \\
0 \\
0 \\
0 \\
0 \\
0 \\
0 \\
0 \\
0 \\
0 \\
0 \\
0\end{array}$} & Глобальные причины: \\
\hline & 1) снижение доли инвестиций в охрану окружающей среды \\
\hline & 2) увеличение выбросов парниковых газов \\
\hline & $\begin{array}{l}\text { 3) международная и национальная политика поощряют декарбонизацию } \\
\text { (общая тенденция декарбонизации) }\end{array}$ \\
\hline & Местные причиньл: \\
\hline & $\begin{array}{l}\text { 4) повышение риска аварийности к } 2030 \text { году до } 80 \% \text { в результате ухудшения } \\
\text { технического состояния устройств из-за недостаточных инвестиционных затрат }\end{array}$ \\
\hline & $\begin{array}{l}\text { 5) более } 42 \text { стихийных бедствий, произошедших на территории России в } \\
2018 \text { году }\end{array}$ \\
\hline & 6) необходимость стимулировать и учитывать использование вторичных ресурсов \\
\hline \multirow{6}{*}{ 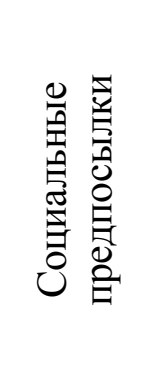 } & Глобальные причинь:: \\
\hline & 1) трудовые кадры умеют работать с цифровыми технологиями \\
\hline & 2) многие сотрудники нефтяных компаний имеют «цифровой» опыт \\
\hline & Локальные причины:: \\
\hline & $\begin{array}{l}\text { 3) российские университеты готовят кадры с учетом требований цифровой } \\
\text { экономики }\end{array}$ \\
\hline & 4) компетентные работники готовы использовать цифровые технологии \\
\hline
\end{tabular}

2) тренд на освоение нетрадиционных месторождений в условиях цифровой трансформации.

В качестве основной методики построения трендов принята диаграмма Исикавы [23], популярный инструмент для анализа корневых причин того или иного факта, но в построении трендов ТЭК России он не использовался. Выбор данного инструмента был обусловлен его наглядностью, гибкостью, простотой анализа, удобством применения, а также данный инструмент прошел проверку временем и доказал свою эффективность в других областях.

1. Тренд на освоение арктических месторождений в условиях цифровой трансформации. Смена парадигмы разработки нефтегазовых месторождений произошла из-за новой научно-технической революции в области добычи нефти и газа. Добыча нефти и газа в Арктике как новая парадигма - это новейшая концепция ценностей, технологических и инженерных решений, направленных на максимизацию роста капитализации и прибыльности ключевых активов нефтегазовых компаний в реальном времени.

Информация, полученная исходя из анализа научных исследований [19-22], была положена в основу построения причинноследственной диаграммы тренда освоения арктических месторождений в условиях цифровой трансформации.

Анализ современного состояния разработки нефтегазовых месторождений Арктики определил основные перспективные направления освоения арктических нефтегазовых месторождений. На рис. 1 представлена причинно-следственная диаграмма Исикавы, которая является основанием для формирования тренда освоения Арктического шельфа в рамках цифровой трансформации ТЭК РФ. 


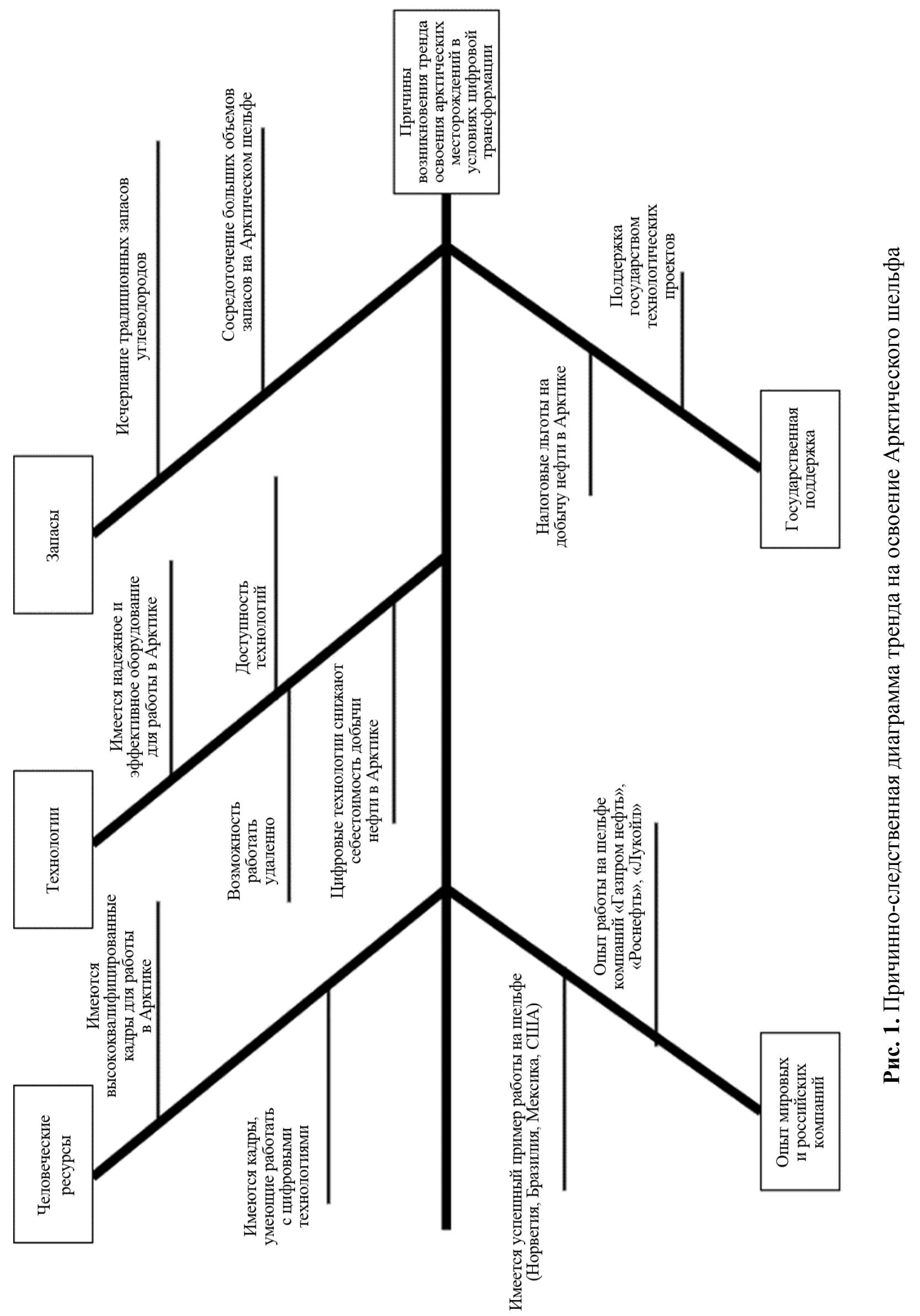




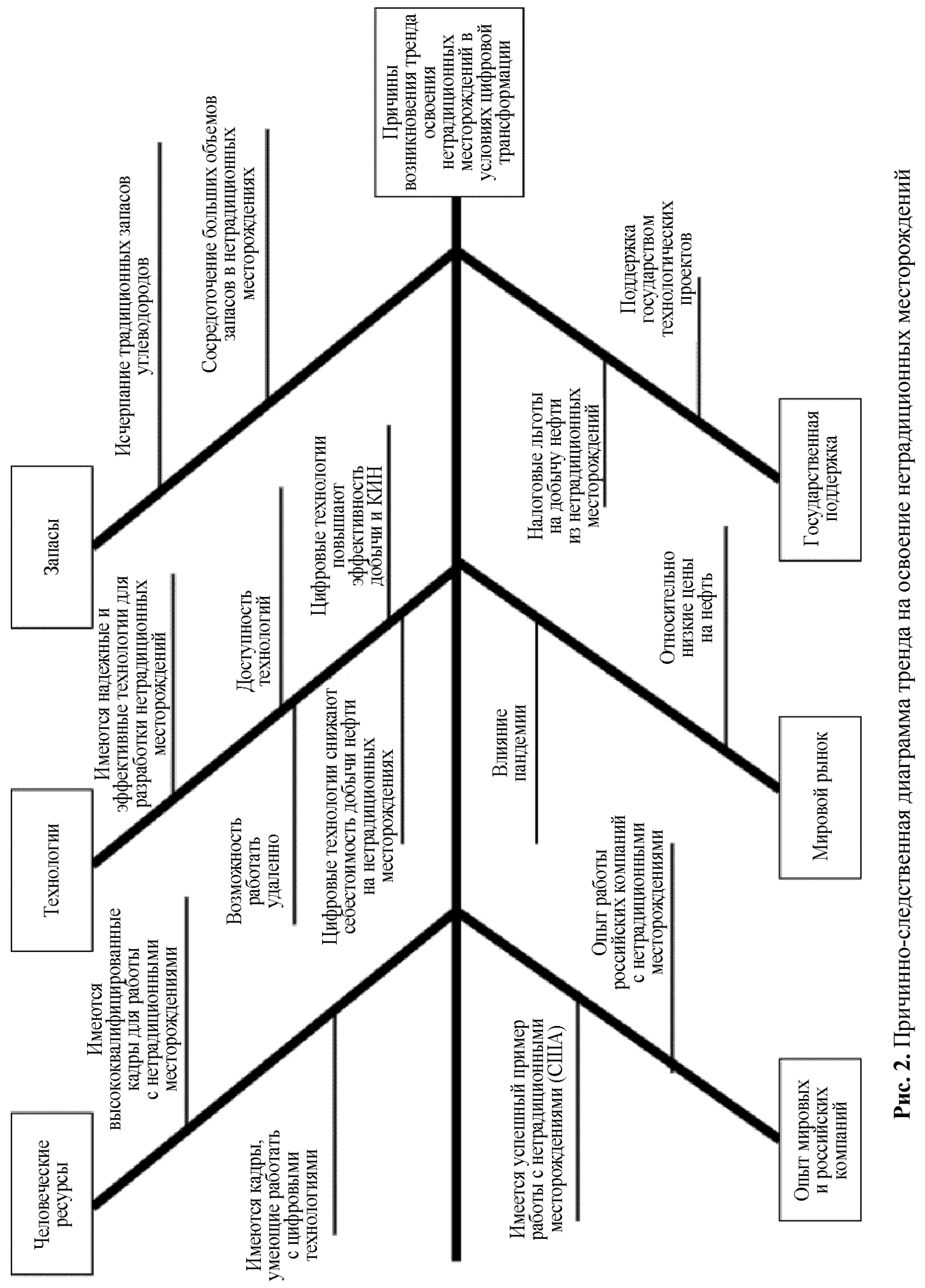


Диаграмма состоит из пяти основных блоков: запасы, технологии, человеческие ресурсы, опыт мировых и российских компаний, государственная поддержка.

Из данной диаграммы видно, что технологии, человеческие ресурсы и государство готовы к освоению Арктики. Также одной из основных причин является исчерпание запасов на традиционных месторождениях. Соответственно, данная диаграмма подтверждает тот факт, что один из трендов развития ТЭК РФ будет направлен на освоение арктических месторождений.

\section{2. Тренд на освоение нетрадицион-} ных месторождений в условиях цифровой трансформации. Предприятия ТЭК РФ переживают непростые времена. Низкие цены на нефть, пандемия и истощение традиционных месторождений подталкивают российские нефтегазовые компании к поиску новых путей развития. Россия, располагающая лишь 13\% мировых запасов сырой нефти, является одной из крупнейших стран в мире по объемам добычи. При нынешней скорости исчерпания традиционных месторождений существует необходимость создания стратегического резерва увеличения уровня добычи нефти и газа из нетрадиционных месторождений, которые выглядят достаточно оптимистично и будут развиваться разнонаправленно в мировом тренде.

Разработка сланцевых месторождений. Российский ТЭК неизбежно приближается к моменту, когда наступит необходимость в разработке и освоении нетрадиционных углеводородов в пластах с низкой проницаемостью, в основном нефти с месторождений баженовской свиты, аналогичных этому, Ачимовских пластов и тюменских месторождений.

Результаты научных исследований [24 27] были положены в основу построения причинно-следственной диаграммы тренда на освоение нетрадиционных месторождений в условиях цифровой трансформации.

Активно внедряются и используются цифровые технологии, что увеличивает эффективность производства и снижает стоимость. Именно эти технологии позволяют работать на нетрадиционных месторождениях и оставаться конкурентоспособными. На рис. 2 представлена причинно-следствен- ная диаграмма тренда на освоение нетрадиционных месторождений в условиях цифровой трансформации ТЭК РФ.

С помощью данной диаграммы обосновано существование тренда на нетрадиционные месторождения. Исчерпание ресурсов, пандемия, низкие цены на нефть вынуждают предприятия ТЭК к изменению вектора своего развития в сторону использования интенсивных методов, а цифровые технологии, поддержка государства и высококвалифицированные кадры обосновывают наличие тренда на освоение нетрадиционных месторождений.

Заключение. В заключение можно утверждать, что предприятия ТЭК РФ следующего поколения разделяют основные положения концепции Industry 4.0 и взяли курс на цифровую трансформацию своей деятельности. Однако нельзя отрицать, что существует ряд проблем и барьеров, возникающих в результате цифровой трансформации этих предприятий.

В рамках цифровой экономики современные предприятия топливно-энергетического комплекса могут получать выгоды, в том числе повышение безопасности труда рабочих, улучшение экологических показателей регионов в целом и как следствие - сохранение баланса биоразнообразия, защиту общественного здоровья, повышение производительности и эффективности труда, сокращение продолжительности цикла «разведка - разработка - добыча», повышение надежности использования оборудования и снижение капитальных затрат. В глобальном масштабе информационно-коммуникационные технологии трансформируют и добывающие отрасли. Для России это дает возможность возглавить разработку и коммерциализацию стимулирующих технологий, интеграцию этих технологий в глобальные операции, а также в широкие социально-экономические и нормативные последствия цифровизации.

Тренды на освоение нетрадиционных месторождений и месторождений Арктического шельфа показывают, в каких направлениях будет двигаться ТЭК РФ следующие десятилетия. Тренд на освоение Арктического шельфа и разработку нетрадиционных месторождений означает, что количество проектов по добыче нефти и газа в Северном Ледови- 
том океане и количество проектов по добыче сланцевой нефти будет только расти, через некоторое время они начнут вносить основной вклад в уровень добычи нефти и газа.

Тренды дают понять, в каких областях потребуется поддержка государства и изменения законодательства для успешной деятельности. Так как ТЭК - это огромный сектор промышленности, который своим развитием создает мультипликативный эффект для развития других отраслей экономики и является как драйвером развития других секторов экономики, так и зависимой стороной от других отраслей и технологий, то заранее намеченные направления развития помогут плавно и оптимально совершить переход компаний к работе на Арктическом шельфе и с нетрадиционными месторождениями. Именно построение трендов даёт возможность адекватно прогнозировать будущее, подстраивать производство под новые задачи и требования, создавать новые подходы к ведению бизнеса, лоббировать законодательную деятельность для развития Арктики и нетрадиционных месторождений. Построение трендов дает время на плавную подготовку и трансформацию всех секторов экономики, связанных с ТЭК.

Благодаря заблаговременной подготовке и прогнозированию с помощью трендов российский топливно-энергетический комплекс сможет не только сохранить свои позиции на мировом рынке, но и повысить свою конкурентоспособность, а также выйти на новый высочайший этап развития.

\section{Литература}

1. Щетинина Н. Ю. Industry 4.0: практические аспекты реализации в российских условиях [Электронный ресурс] // Модели, системы, сети в экономике, технике, природе и обществе. - 2017. — №1 (21). - Peжим доступа: https:/cyberleninka.ru/article/n/ industriya-4-0-prakticheskie-aspekty-realizatsiiv-rossiyskih-usloviyah/ (Дата обращения: 29.10.2020).

2. Никитенко С.М., Гоосен Е.В., Пахомова Е. О. Мировой инновационный проект «Industry 4.0» и перспективы комплексного освоения недр в топливно-энергетическом комплексе России [Электронный ресурс] // Инновации. — 2019. — №10 (252). — Pe- жим доступа: https://cyberleninka.ru/article/n/ mirovoy-innovatsionnyy-proekt-industriya-4-0i-perspektivy-kompleksnogo-osvoeniya-nedrv-toplivno-energeticheskom-komplekse-rossii/ (Дата обращения: 26.09.2020).

3. Пиголева И.В., Миловидов К.Н. Мировая нефтегазохимия: основные тенденции развития в условиях трансформации мировой энергетики // Микроэкономика. - 2018. №5. - C. 22-30.

4. Dmitrievskiy A.N., Eremin N.A., Filippova D. S., Safarova E.A. Digital oil and gas complex of Russia // Georesursy, 2020. - Special Issue. - P. 32-35.

5. Линник Ю.Н., Кирюхин М.А. Цифровые технологии в нефтегазовом комплексе [Электронный ресурс] // Вестник ГУУ. 2019. - №7. - Режим доступа: https:// cyberleninka.ru/article/n/tsifrovye-tehnologii-vneftegazovom-komplekse/ (Дата обращения: 26.09.2020).

6. Тчаро Х., Воробьев А.Е., Воробьев К.А. Цифровизация нефтяной промышленности: базовые подходы и обоснование «интеллектуальных» технологий [Электронный ресурс] // Вестник евразийской науки. - 2018. - №2. - Режим доступа: https://cyberleninka.ru/article/n/tsifrovizatsiyaneftyanoy-promyshlennosti-bazovye-podhodyi-obosnovanie-intellektualnyh-tehnologiy/ (Дата обращения: 28.09.2020).

7. Shishkin A.N., Timashev E.O., Solovykh V.I., Volkov M. G., Kolonskikh A. V. Bashneft digital transformation: From concept design to implementation. Neftyanoe Khozyaystvo Oil Industry. - 2019. - №3. - P. 7-12.

8. «Цифровая энергетика»: новые возможности и вызовы для ТЭК [Электронный pecypc]. - Режим доступа: https://www. gazprom-neft.ru/press-center/sibneft-online/ archive/2020-july-august/4877850/ (Дата обращения: 23.09.2020).

9. Khan W.Z., Aalsalem M.Y., Gharibi W., Arshad $Q$. Oil and gas monitoring using wireless sensor networks: Requirements, issues and challenges // Paper presented at the Proceeding - 2016 International Conference on Radar, Antenna, Microwave, Electronics, and Telecommunications. - ICRAMET, 2016. - P. 31-35.

10. Мозохин Ан. Е., Мозохин Ал. Е. Анализ перспективного развития энергетических систем в условиях цифровой трансформации 
Российской экономики [Электронный ресурс] // Научно-технический вестник информационных технологий, механики и оптики. - 2020. — №1. — Режим доступа: https:// cyberleninka.ru/article/n/analiz-perspektivnogorazvitiya-energeticheskih-sistem-v-usloviyahtsifrovoy-transformatsii-rossiyskoy-ekonomiki (Дата обращения: 29.10.2020).

11. Халов О., Юдин Д. А. Влияние санкций на развитие нефтегазового сектора Российской Федерации [Электронный ресурс]// Инновации и инвестиции. - 2020. - №8. - Peжим доступа: https:/cyberleninka.ru/article/n/ vliyanie-sanktsiy-na-razvitie-neftegazovogosektora-rossiyskoy-federatsii/ (Дата обращения: 29.10.2020).

12. Блокчейн для «Приразломной» [Электронный ресурс]. — Режим доступа: https:// www.gazprom-neft.ru/press-center/sibneftonline/archive/2018-april/1533012/ (Дата обращения: 23.09.2020).

13. О цифровой трансформации «Газпром нефти» и технологических трендах нефтяной отрасли [Электронный ресурс]. Режим доступа: https:/www.gazprom-neft.ru/ press-center/lib/4029430/ (Дата обращения: 23.09.2020).

14. Hermann M., Pentek T., Otto B. Design principles for industrie 4.0 scenarios // Paper presented at the Proceedings of the Annual Hawaii International Conference on System Sciences. - March, 2016. — Pp. 3928-3937.

15. GafurovA.R., Skotarenko O.V., Nikitin Y.A., Plotnikov V.A. Digital transformation prospects for the offshore project supply chain in the Russian Arctic // Paper presented at the IOP Conference Series: Earth and Environmental Science. - 2020. - №539 (1).

16. Golubev S.S., Efremov A.A. Development of digital technologies for the arctic zone of the Russian Federation. Journal of Advanced Research in Law and Economics. - 2019. №10 (8). - Pp. 2346-2356.

17. Didenko N.I. Concept and mechanism for managing the digital transformation of arctic target subspaces and spheres of vital activity // Paper presented at the IOP Conference Series: Materials Science and Engineering. - 2020. №940 (1).

18. Kulyasov N.S., Shipkova O.T., Zavialov A. E., Charyyarova G.D. Directions of development of digitalization of the oil industry in the russian federation // Paper presented at the IOP Conference Series: Materials Science and Engineering. — 2020. — №919 (6).

19. Zeynalli A., Butdayev R., Salmanov V. Digital transformation in oil and gas industry // Paper presented at the Society of Petroleum Engineers - SPE Annual Caspian Technical Conference 2019, CTC 2019.

20. Chernova E. G., Razmanova S. V. Structural shifts in the oil and gas industry: Key factors, indicators, consequences // Vestnik SPbGU. Ekonomika. — 2017. — №4. - Pp. 622-640.

21. Nixon J. Digitalization deployed: Lessons learned from early adopters // Paper presented at the Proceedings of the Annual Offshore Technology Conference. - May 2020.

22. Бажитов А.В., Ермолина Л.В., Овчинников $K . A$. Трансформация нефтегазового сектора в условиях цифровизации [Электронный ресурс] // Эксперт: теория и практика. — 2019. - №3 (3). - Режим доступа: https://cyberleninka.ru/article/n/transformatsiyaneftegazovogo-sektora-v-usloviyah-tsifrovizatsii (Дата обращения: 29.10.2020).

23. Федюкин В.К. Управление качеством процессов. - СПб.: Питер, 2005. - 202 с.

24. Le Turdu C., Pugh A., Fraser C., Nollet S., Castagnac C., Stabell F., Tushingham K. Benefits of digital for better exploration planning and execution // Paper presented at the 1st EAGE Digitalization Conference and Exhibition. - 2020 .

25. What are the three key actions being used by leading oil and gas companies to start their digital journey? Accenture Blog. - 2017.

26. World Economic Forum. Digital transformation initiative. Digital Transformation Initiative. Retrieved from www.scopus.com. 2017.

27. Razmanova S. V., Andrukhova O.V. Oilfield service companies as part of economy digitalization: Assessment of the prospects for innovative development // Journal of Mining Institute. — 2020. — №244 (4). — Pp. 482-492.

\section{References}

1. Shhetinina N. Ju. Industry 4.0: prakticheskie aspekty realizacii $\mathrm{v}$ rossijskih uslovijah [Industry 4.0: practical aspects of implementation in Russian conditions] [Jelektronnyj resurs]// Modeli, sistemy, seti v jekonomike, 
tehnike, prirode i obshhestve [Models, systems, and networks in economics, technology, nature, and society]. - 2017. - №1 (21). - URL: https://cyberleninka.ru/article/n/industriya-4-0prakticheskie-aspekty-realizatsii-v-rossiyskihusloviyah/ (Date accessed: 29.10.2020).

2. Nikitenko S.M., Goosen E.V., Pahomova E.O. Mirovoj innovacionnyj proekt «Industry 4.0 » i perspektivy kompleksnogo osvoenija nedr $\mathrm{v}$ toplivno-jenergeticheskom komplekse Rossii [World innovation project «Industry 4.0» and prospects for integrated development of mineral resources in the fuel and energy complex of Russia] [Jelektronnyj resurs] // Innovacii [Innovation]. — 2019. — №10 (252). — URL: https://cyberleninka.ru/article/n/mirovoy-innovatsionnyy-proekt-industriya-4-0-i-perspektivykompleksnogo-osvoeniya-nedr-v-toplivno-energeticheskom-komplekse-rossii/ (Date accessed: 26.09.2020).

3. Pigoleva I. V., Milovidov K.N. Mirovaja neftegazohimija: osnovnye tendencii razvitija $\mathrm{v}$ uslovijah transformacii mirovoj jenergetiki [World oil and gas chemistry: the main trends of development in the conditions of transformation of world energy] // Mikrojekonomika. 2018. - №5. - Pp. 22-30.

4. Dmitrievskiy A. N., Eremin N.A., Filippova D.S., Safarova E.A. Digital oil and gas complex of Russia // Georesursy, 2020. - Special Issue. - P. 32-35.

5. Linnik Ju. N., Kirjuhin M.A. Cifrovye tehnologii $\mathrm{v}$ neftegazovom komplekse [Digital technologies in the oil and gas complex] [Jelektronnyj resurs] // Vestnik GUU. - 2019. №7. - URL: https://cyberleninka.ru/article/n/ tsifrovye-tehnologii-v-neftegazovom-komplekse/ (Date accessed: 26.09.2020).

6. Tcharo H., Vorob'ev A. E., Vorob'ev K.A. Cifrovizacija neftjanoj promyshlennosti: bazovye podhody i obosnovanie «intellektual'nyh» tehnologij [Digitalization of the oil industry: basic approaches and justification of «intelligent» technologies] [Jelektronnyj resurs] // Vestnik evrazijskoj nauki [Bulletin of Eurasian Science]. — 2018. - №2. — URL: https:// cyberleninka.ru/article/n/tsifrovizatsiya-neftyanoy-promyshlennosti-bazovye-podhody-iobosnovanie-intellektualnyh-tehnologiy/ (Date accessed: 28.09.2020).

7. Shishkin A.N., Timashev E.O., Solovykh V.I., Volkov M.G., Kolonskikh A.V. Bash- neft digital transformation: From concept design to implementation. Neftyanoe Khozyaystvo Oil Industry. - 2019. - №3. - P. 7-12.

8. «Cifrovaja jenergetika»: novye vozmozhnosti i vyzovy dlja TJeK [«Digital Energy»: new opportunities and challenges for the fuel and energy sector] [Jelektronnyj resurs]. — URL: https://www.gazprom-neft.ru/press-center/sibneftonline/archive/2020-july-august/4877850/ (Date accessed: 23.09.2020).

9. Khan W.Z., Aalsalem M.Y., Gharibi W., Arshad Q. Oil and gas monitoring using wireless sensor networks: Requirements, issues and challenges // Paper presented at the Proceeding - 2016 International Conference on Radar, Antenna, Microwave, Electronics, and Telecommunications. - ICRAMET, 2016. - P. 31-35.

10. Mozohin An. E., Mozohin Al. E. Analiz perspektivnogo razvitija jenergeticheskih sistem v uslovijah cifrovoj transformacii Rossijskoj jekonomiki [Analysis of the prospective development of energy systems in the conditions of digital transformation of the Russian economy] [Jelektronnyj resurs] // Nauchno-tehnicheskij vestnik informacionnyh tehnologij, mehaniki i optiki [Scientific and Technical Bulletin of information Technologies, Mechanics and Optics]. 2020. — №1. — URL: https://cyberleninka.ru/ article/n/analiz-perspektivnogo-razvitiya-energeticheskih-sistem-v-usloviyah-tsifrovoy-transformatsii-rossiyskoy-ekonomiki (Date accessed: 29.10.2020).

11. Halov O., Judin D.A. Vlijanie sankcij na razvitie neftegazovogo sektora Rossijskoj Federacii [The impact of sanctions on the development of the oil and gas sector of the Russian Federation] [Jelektronnyj resurs] // Innovacii i investicii [Innovations and Investments]. 2020. — №8. — URL: https://cyberleninka.ru/ article/n/vliyanie-sanktsiy-na-razvitie-neftegazovogo-sektora-rossiyskoy-federatsii/ (Date accessed: 29.10.2020).

12. Blokchejn dlja «Prirazlomnoj» [Blockchain for Prirazlomnaya] [Jelektronnyj resurs]. - URL: https://www.gazprom-neft. ru/press-center/sibneft-online/archive/2018april/1533012/ (Date accessed: 23.09.2020).

13. O cifrovoj transformacii «Gazprom nefti» i tehnologicheskih trendah neftjanoj otrasli [On the digital transformation of Gazprom Neft and technological trends in the oil industry] [Jelektronnyj resurs]. — URL: https:// 
www.gazprom-neft.ru/press-center/lib/4029430/ (Date accessed: 23.09.2020).

14. Hermann M., Pentek T., Otto B. Design principles for industrie 4.0 scenarios // Paper presented at the Proceedings of the Annual Hawaii International Conference on System Sciences. - March, 2016. — Pp. 3928-3937.

15. Gafurov A.R., SkotarenkoO.V., Nikitin Y.A., Plotnikov V.A. Digital transformation prospects for the offshore project supply chain in the Russian Arctic // Paper presented at the IOP Conference Series: Earth and Environmental Science. - 2020. - №539 (1).

16. Golubev S.S., Efremov A.A. Development of digital technologies for the arctic zone of the Russian Federation. Journal of Advanced Research in Law and Economics. - 2019. №10 (8). - Pp. 2346-2356.

17. Didenko N.I. Concept and mechanism for managing the digital transformation of arctic target subspaces and spheres of vital activity // Paper presented at the IOP Conference Series: Materials Science and Engineering. — 2020. №940 (1).

18. Kulyasov N.S., Shipkova O.T., Zavialov A.E., Charyyarova G.D. Directions of development of digitalization of the oil industry in the russian federation // Paper presented at the IOP Conference Series: Materials Science and Engineering. - 2020. — №919 (6).

19. Zeynalli A., Butdayev R., Salmanov V. Digital transformation in oil and gas industry // Paper presented at the Society of Petroleum Engineers - SPE Annual Caspian Technical Conference 2019, CTC 2019.

20. Chernova E. G., Razmanova S. V. Structural shifts in the oil and gas industry: Key fac- tors, indicators, consequences // Vestnik SPbGU. Ekonomika. - 2017. - №4. - Pp. 622-640.

21. Nixon J. Digitalization deployed: Lessons learned from early adopters // Paper presented at the Proceedings of the Annual Offshore Technology Conference. - May 2020.

22. Bazhitov A.V., Ermolina L.V., Ovchinnikov K.A. Transformacija neftegazovogo sektora $\mathrm{v}$ uslovijah cifrovizacii [Transformation of the oil and gas sector in the conditions of digitalization] [Jelektronnyj resurs] // Jekspert: teorija i praktika [Expert: theory and practice]. 2019. — №3 (3). — URL: https://cyberleninka. $\mathrm{ru} /$ article/n/transformatsiya-neftegazovogo-sektora-v-usloviyah-tsifrovizatsii (Date accessed: 29.10.2020).

23. Fedjukin V.K. Upravlenie kachestvom processov [Process quality management]. Saint Petersburg: Piter, 2005. - 202 p.

24. Le Turdu C., Pugh A., Fraser C., Nollet S., Castagnac C., Stabell F., Tushingham K. Benefits of digital for better exploration planning and execution // Paper presented at the 1st EAGE Digitalization Conference and Exhibition. -2020 .

25. What are the three key actions being used by leading oil and gas companies to start their digital journey? Accenture Blog. — 2017.

26. World Economic Forum. Digital transformation initiative. Digital Transformation Initiative. Retrieved from www.scopus.com. - 2017.

27. Razmanova S. V., Andrukhova O.V. Oilfield service companies as part of economy digitalization: Assessment of the prospects for innovative development // Journal of Mining Institute. - 2020. — №244 (4). — Pp. 482-492. 


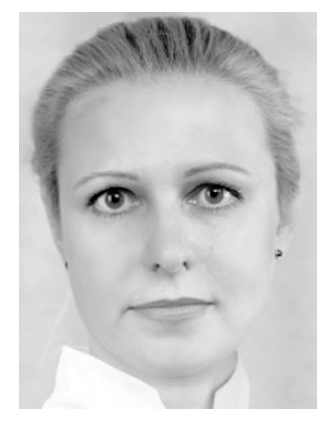

Зайченко Ирина Михайловна - кандидат экономических наук, доцент Высшей школы управления и бизнеса Санкт-Петербургского политехнического университета Петра Великого. Сфера научных интересов: стратегическое управление предприятиями, в том числе разработка и реализация стратегии развития предприятия; анализ и совершенствование систем корпоративного управления; анализ отрасли и конкуренции в ней, анализ и совершенствование систем управления персоналом на предприятиях различных организационно-правовых форм; осуществление цифровой трансформации бизнеса.

Zaychenko Irina Mikhailovna - Candidate of Economic Sciences, Associate Professor of the Higher School of Management and Business, Peter the Great St. Petersburg Polytechnic University. Research interests: strategic management of enterprises, including the development and implementation of enterprise development strategies; analysis and improvement of corporate governance systems; analysis of the industry and competition in it, analysis and improvement of personnel management systems at enterprises of various organizational and legal forms; implementation of digital business transformation.

195251, г. Санкт-Петербург, ул. Политехническая, 29

29 Polytekchnicheskaya st., 195251, Saint Petersburg, Russia

E-mail: zaychenko@spbstu.ru

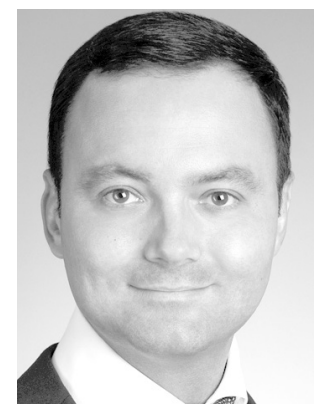

Фадеев Алексей Михайлович - доктор экономических наук, Главный научный сотрудник Института экономических проблем им. Г.П. Лузина, профессор Высшей школы управления и бизнеса Санкт-Петербургского политехнического университета Петра Великого. Сфера научных интересов: стратегическое управление нефтегазовым комплексом в Арктике, теория и практика стратегирования, логистика и обеспечение энергетических проектов.

Fadeev Alexey Mikhailovich - Doctor of Economic Sciences, Chief Researcher of the Luzin Institute for Economic Problems, Professor of the Higher School of Management and Business of Peter the Great St. Petersburg Polytechnic University. Research interests: strategic management of the oil and gas complex in the Arctic, theory and practice of strategizing, logistics and support of energy projects.

184209 , г. Апатиты, ул. Ферсмана, 24a

24a Fersmana st., 184209, Apatity, Russia

E-mail: alexfadeev79@gmail.com 


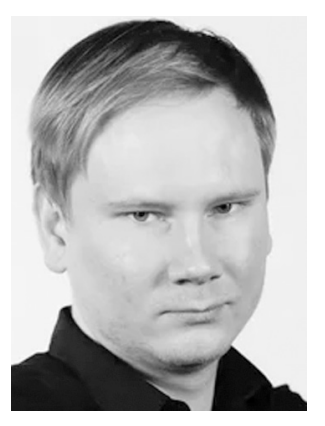

Костюченко Александр Игоревич - бакалавр, Ярославский государственный технический университет, магистр Санкт-Петербургского политехнического университета Петра Великого. Сфера научных интересов: логистика арктических месторождений, управление проектами, цифровые технологии в нефтегазовой сфере.

Kostyuchenko Alexander Igorevich - Bachelor's Degree, Yaroslavl State Technical University, Master's Degree, Peter the Great St. Petersburg Polytechnic University. Research interests: logistics of Arctic fields, project management, digital technologies in the oil and gas sector.

195251, г. Санкт-Петербург, ул. Политехническая, 29 29 Polytekchnicheskaya st., 195251, Saint Petersburg, Russia

E-mail: sascha.kostyuchenko@gmail.com 